[ROSANE FEIJÃO]

Doutora em Comunicação (UERJ)

E-mail: fejjão.rosane@gmail.com

\title{
"Yes! Nós temos biquíni": uma exposição para pensar sobre as relações entre moda, corpo, arte e cidade
}

"Yes! Nós temos biquíni": an exhibition to think about the relations between fashion, body, art and city

Curadoria: Lilian Pacce Local e periodo: Centro Cultural Banco do Brasil, Rio de Janeiro. De 15 de maio a 10 de julho de 2017 
No texto de apresentação da exposição Yes! Nós temos biquíni, a curadora, Lilian Pace, assume que o principal objetivo da exibição é "mostrar a força" do que ela chama "a menor peça do vestuário feminino" - uma peça que, embora tenha nascido por iniciativa do estilista francês Louis Réard, parece ter encontrado no Brasil, especialmente nas praias cariocas, sua mais perfeita tradução, tornando os modelos aqui produzidos, ainda segundo a curadora, uma "referência em moda praia".

Nos diversos ambientes ocupados pela mostra, espalhados pelo segundo andar do Centro Cultural Banco do Brasil do Rio de Janeiro, o foco se manteve nos trajes de banho, mas os desdobramentos advindos do desnudamento feminino pelos hábitos praianos foram, também, cuidadosamente iluminados. Isso pode ser percebido, por exemplo, na atenção dada à apresentação dos manequins que povoam a primeira sala, dedicada à história dos trajes de banho: a superfície geralmente lisa da fibra de vidro recebeu, além da cor bronzeada, uma textura granulada, lembrando o efeito da areia fina sobre a pele.

Este primeiro ambiente desperta o interesse pela história da moda dos trajes de banho. Uma linha do tempo, formada por fotografias, ilustrações e textos, destaca as principais polêmicas causadas pela progressiva exposição do corpo feminino desde a adoção, ainda na primeira década do século XX, do maiô colante pela nadadora olímpica australiana Annette Kellermann - até então um traje exclusivamente masculino. 0 ambiente foi tratado de forma a evocar os sentidos e as memórias de cada visitante, servindo como estímulo para que ele se reconheça como parte daquela história: a iluminação em cores quentes lembra o entardecer; o tablado ondulado, onde pousam os manequins, imita o movimento da areia; os sons que misturam pregões de ambulantes com a algazarra típica de domingos ensolarados junto ao mar remetem à atmosfera que transformou o território da praia, por muito tempo vazio', na maior área de lazer da cidade do Rio de Janeiro.

Enquanto a primeira sala cobre mais de um século de história, 0 ambiente seguinte expõe alguns momentos recentes que muitos gostariam de ver esquecidos, com criações de gosto duvidoso, como o biquíni que ostentava uma generosa fenda na parte de trás da calcinha, deixando exposta certa parte da anatomia ainda hoje cercada por tabus. A peça invertia 0 que o modelo apelidado de "fio dental" havia exposto alguns anos antes, despertando discussões que, embora acaloradas, duraram pouco tempo, já que o uso do modelo ficou limitado à passarela de uma semana de moda.

Tais proposições, mesmo que não tenham sido vistas nas areias do nosso extenso litoral, levantam questões sobre as relações entre corpo e moda, relações estas que, no caso dos trajes de banho, apresentam uma 
trajetória marcada pela tensão entre liberdade e controle, desaguando no que Anne-Marie Sohn (2011, p. 109) definiu como uma "erosão progressiva do pudor", desenvolvida ao longo do século XX e estendendo-se pelo XXI.

Mas é possivel pensar, também, em uma transformação do conceito de pudor, deixando de vinculá-lo simplesmente ao recato, mas relacionando- o a uma nova moral, a "moral da boa forma" que, segundo Goldenberg e Ramos (2002, p. 25), tornou cada indivíduo responsável por sua aparência física, por preparar o próprio corpo para que ele possa ser exposto publicamente:

Pode-se dizer que, sob a moral da "boa forma", um corpo trabaIhado, cuidado, sem marcas indesejáveis (rugas, estrias, celulites, manchas) e sem excessos (gorduras, flacidez) é o único que, mesmo sem roupas, está decentemente vestido (GOLDENBERG; RAMOS, 2002, p. 29).

No áudio "Corpo feminino e o imaginário", que podia ser escutado durante a visita à exposição e também foi disponibilizado no site do $\mathrm{CCBB}^{2}$, surge a pergunta: "0 que é 'corpo de praia'?". A expressão indica o quanto os hábitos balneários determinaram uma reformatação das aparências, quando as praias da Zona Sul do Rio de Janeiro passaram

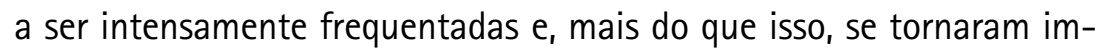
portantes locais de sociabilidade - lugares, portanto, propícios ao surgimento e difusão de modismos.

A provocação da curadora ecoa nas obras de arte dispostas pelo ambiente: instalações, videoinstalações, esculturas, fotografias, desenhos e pinturas exploram o crescente desnudamento do corpo feminino pela moda. Se, por um lado, tal desnudamento proporcionou às mulheres experimentarem de forma mais completa as sensações produzidas pelo contato com a natureza e se afirmarem como as legitimas administradoras do próprio corpo, por outro, induziu ao surgimento de práticas corporais tão complexas quanto perversas. É o que sugerem as obras de Marcela Tiboni, "Estudo para desenho de corpo feminino": três fotografias que exibem o corpo nu da artista, sobre o qual foram desenhadas linhas que remetem tanto aos estudos de anatomia quanto às marcações efetuadas por cirurgiões plásticos sobre o corpo de suas pacientes.

A expressão "corpo de praia" poderia se referir à ação do meio sobre o corpo, ou seja, o que acontece ao corpo daqueles que frequentam com certa assiduidade os ambientes à beira mar. No entanto, a expressão inverte essa lógica: o "corpo de praia" é aquele que é preparado para ir à praia. Ou seja, embora o ambiente e os hábitos relacionados às praias estejam envolvidos pela aura do "saudável" e do "natural", estamos aqui falando de 
atos, comportamentos ou procedimentos que moldam os corpos de acordo com a cultura e a moda. 0 "corpo de praia" é, portanto, uma construção cultural, um mito contemporâneo, no sentido que Barthes (2003, p. 200) dá a essa expressão, ou seja, não é algo que surge da natureza das coisas, mas "[...] de um uso social que se acrescenta à pura matéria".

Outro setor da exposição explora o flerte da moda com a arte, colocando lado a lado trajes de banho e as obras de arte que serviram de inspiração para estilistas e criadores de moda praia. No mais das vezes, o que se pode perceber é a transformação de ilustrações, fotografias e pinturas em estampas para tecidos que se transformaram em biquínis e maiôs. A exceção é a parceria entre o artista Jorge Fonseca e o estilista David Azulay, tendo o primeiro contribuído pessoalmente, segundo depoimento da curadora ${ }^{3}$, para a confecção das peças, trabalhando nos bordados que marcaram aquela coleção.

Embora a mostra tenha um caráter abrangente, contando tanto com peças emprestadas de acervos internacionais quanto com outras provenientes de diferentes estados do país, o Rio de Janeiro aparece como protagonista desse enredo que entrelaça a praia e a moda. A cidade não é apenas palco ou passarela para a moda praia, ela é uma das personagens principais - uma personagem que, com suas constantes mudanças, cria novas demandas para os corpos que a povoam.

Desde a década de 1920 as praias da Zona Sul passaram a abrigar um contingente expressivo de banhistas, que ali permaneciam por horas seguidas - e não apenas o tempo necessário para o banho de mar, como costumava acontecer até a década anterior. As imagens da "nympha carioca"4 ou das "sereias de maillot"5 em poses estudadas sob o sol passaram a ser parte imprescindivel da paisagem da metrópole-balneário.

A mostra não explorou essas primeiras - e geralmente anônimas personagens das areias cariocas, mas lá estão os registros de fotógrafos e modelos famosos - "de Dalma Callado por Tripolli nos anos 1970 a Gisele Bündchen por Jacques Dequeker nos anos 2000", segundo texto da própria curadoria -, que circularam em exposições e revistas, nacionais e estrangeiras, colaborando para difundir as praias do Rio de Janeiro e os modismos que nelas eram criados como pontos de destaque do imaginário da cidade, e, por consequência, também do país.

Tais fotografias nos fazem acompanhar as diferentes versões dadas ao biquíni ao longo das décadas, expondo partes do corpo que por muito tempo haviam se mantido cobertas; desenhando molduras para colos, barrigas e nádegas; criando tensões e alimentando fantasias com o auxílio das novas tecnologias que, aplicadas aos tecidos e às modelagens, transformaram os trajes de banho em uma segunda pele, que parece colada à original. 
Em outra sala, o ambiente e o estilo de vida carioca transbordam das ilustrações de Alceu Penna que circularam na Revista Cruzeiro em meados do século passado e das gravuras de Paulo von Poser (Copacabana Palace, 2011), de Carla Caffé (Dois irmãos, 2006) e de Filipe Jardim (Mirante Leblon, 2012), que constroem suas composições a partir da harmonia e do contraste entre os elementos humanos, a paisagem natural e o ambiente urbano da cidade que já foi descrita como "purgatório da beleza e do caos"6.

Neste ambiente dedicado à cidade, merece destaque a sequência de fotografias de Cartiê Bressão, codinome do fotógrafo Pedro Garcia, que, com ironia e olhar aguçado, compõe uma crônica bem-humorada das praias da Zona Sul. As legendas, que brincam com a língua francesa misturando-a ao português ("Mesdames et messieurs: le bumbum carioca"), potencializam a carioquice das cenas cotidianas mais banais, mas que parecem ser possiveis apenas naquela cidade, onde se dá, segundo o artista, "[...] uma combinação única de geografia, clima e personalidade dos habitantes" (em entrevista a OLIVEIRA, 2015).

0 grande painel que preenche toda a parede da última sala, uma imensa fotografia aérea de Cássio Vasconcellos (2011), proporciona um último impacto ao visitante. Talvez mesmo um duplo impacto: o primeiro, dado pela dimensão da imagem, e o segundo, pelo estranhamento advindo da praia retratada. Depois de tantas odes à cidade do Rio de Janeiro, é impossivel identificar a praia ali representada como sendo carioca. Não é só a largura da faixa de areia, muito mais extensa do que as de Ipanema ou Copacabana, mas a própria forma como o espaço é ocupado, exibindo uma densidade quase homogênea, com trechos em que os guarda-sóis aparecem organizadamente dispostos em colunas duplas. Falta o caos da canção interpretada por Fernanda Abreu. Na legenda, a obra é identificada como "A Praia". Ali, no entanto, ela parece ser apenas "uma praia", onde não se vê nem a cidade homenageada, nem os trajes de banho aos quais se refere a exposição.

É uma pena que a mostra tenha sido um evento restrito ao Rio de Janeiro. Com muitos pontos positivos, era de se esperar que ela circulasse pelo país, ao menos por São Paulo, Brasília e Belo Horizonte, cidades onde se encontram outras sedes do CCBB. As exposições que tomam a moda por tema ainda são raras em terras brasileiras e Yes, nós temos biquíni teve o mérito de exibir uma visão abrangente sobre o assunto, estendendo a discussão para além do vestuário, oferecendo ao público uma oportunidade de refletir sobre o próprio cotidiano, de questionar preconceitos, de experimentar sensações e revisitar memórias. 


\section{NOTAS}

${ }^{1}$ A expressão faz referência ao livro Território do vazio: a praia e o imaginário ocidental, de Alain Corbin (1989).

2 Disponivel em: http://culturabancodobrasil.com.br/portal/yes-nos-temos-biquini/. Acesso em: 25 ago. 2017.

3 "Um tour pela expô 'Yes! Nós Temos Biquíni!"', vídeo promocional da exposição. Disponivel em: https:// www.youtube.com/watch? $\mathrm{v}=\mathrm{dR5}$ eqSt1qgA. Acesso em: 28 ago. 2017.

${ }^{4}$ Expressão utilizada como legenda para a capa da revista Fon-Fon de 8 de março de 1913, que trazia a ilustração de uma banhista.

${ }^{5}$ Expressão utilizada no texto "Verão carioca", publicado pela revista Para Todos, de 4 de fevereiro de 1928. 6 "Rio quarenta graus", canção composta por Fernanda Abreu, Fausto Fawcett e Laufer (1992).

\section{REFERÊNCIAS}

BARTHES, Roland. Mitologias. São Paulo: Difel, 2003.

CORBIN, Alain. 0 território do vazio:a praia e o imaginário ocidental. São Paulo: Companhia das Letras, 1989.

GALVÃO, Sarah S. Quase Local RIO: Pedro Garcia, o Cartiê Bressão. Almost Locals, Rio de Janeiro, 22 jun. 2015. Disponivel em: https://www.almostlocals.com/quase-local-rio-pedro-garcia-o-cartiebressao/. Acesso em: 12 set. 2017.

GOLDENBERG, Mirian; RAMOS, Marcelo S. A civilização das formas: o corpo como valor. In: GOLDENBERG, M. (Org.). Nu e vestido:dez antropólogos revelam a cultura do corpo carioca. Rio de Janeiro: Record, 2002. p. 19-40.

-Marie. 0 corpo sexuado. In: COURTINE, Jean-Jacques (Dir.). História do Corpo:3. As mutações do olhar: o século XX. Petrópolis: Vozes, 2011. p. 109-154. 